\title{
On the Evaluation Index System of E-commerce in Ethnic Regions in China Based on Factor Analysis
}

\author{
Haiying $\mathrm{Ma}^{*}$ \\ School of Economics, Northwest Minzu University \& Provincial Key Laboratory of E-commerce of \\ Ethnic Information, Northwest Minzu University, Lanzhou (730124), P.R.China \\ Ixmahaiying8888@163.com
}

\section{Keywords: Factor analysis; Electronic commerce; Index system; Ethnic regions}

\begin{abstract}
E-commerce as an important branch of electronic commerce in ethnic minority regions, has become an important means of China's enterprises to carry out international trade, become the steady growth of foreign trade in our country, the driving force of the structure. For investigation in ethnic minority regions in our country electronic commerce application level, E-business processes based on ethnic regions established indices for evaluating e-commerce application status in national regions and design the corresponding questionnaire, under the guidance of the ministry of commerce, enterprises survey, conducted by Canton fair, in to the foreign trade enterprise to carry on the large-scale questionnaire survey; Then, the evaluation index was modified by the factor analysis method, and the two-level evaluation index system with weight was obtained. According to the result of data analysis, this paper summed up five of e-commerce development in national regions have important influence on index, index system is also used to our country's electronic commerce application in national regions are analyzed, and the problems existing in the electronic commerce development in national regions, and put forward the corresponding policy recommendations according to the results of the concrete analysis.
\end{abstract}

\section{Introduction}

In 2012, the import and export volume of Chinese goods surpassed that of the United States for the first time, becoming the largest country with the largest import and export trade in the world, but the growth rate did not meet the target of development. Under such circumstances, it is helpful for our country to actively adapt to the new trend of international trade development, expand the export channels and maintain the steady growth of foreign trade import and export. Commerce Department statistics show that at present our country electronic commerce platform in national regions has more than 1800 enterprises, through all kinds of platform to carry out the national region within the territory of e-commerce enterprise has more than $20 \mathrm{~m}$, ethnic minority regions in 2013 e-commerce import and export turnover reached $\$ 1.4$ billion, up $43.3 \%$ from a year earlier. As an important branch of e-commerce in China's strategic emerging industries during the 12th five-year plan period, e-commerce in ethnic regions has become an important means for Chinese enterprises to carry out international trade. The closely followed China (Shanghai) pilot free trade zone also proposed to speed up the development of e-commerce services in ethnic regions, hoping to create a new Internet channel for import and export trade. For a comprehensive understanding of the application situation of electronic commerce in national regions, under the guidance of the ministry of commerce, in May 2015, Shanghai university of science and technology to our country enterprise to carry out the national area of E-commerce to be carried on the thorough investigation, through a certain number of e-commerce platform in foreign trade, foreign trade enterprises and production enterprises, summarized the practice data, the ethnic minority regions in our country in recent years electronic commerce application experience and existing problems, and e-commerce management specification for the ministry of commerce issued national regions provide reference opinions and decision support.

For ethnic minority regions of e-commerce research is mainly focused on the influence of e-commerce on international trade research, ethnic minority regions to the existing tax and trade disputes solution legal question discussion, ethnic minority regions, such as trade impact analysis of the 
$\mathrm{RMB}$, etc; In terms of evaluation index system construction, the research of electronic commerce in ethnic regions is still need further development, but for the economic benefits of foreign trade enterprises, foreign trade growth mode and growth quality, e-commerce enterprise operation effect, e-commerce credit, at present, the construction of the performance evaluation index system of all have a lot of research. At present, the research on the statistic index system of electronic commerce also provides important reference value for this paper. Ceng Hong (2005) argue that the supply and demand of e-commerce statistics, trade statistics and trade flow statistics is the main form of statistical target system in electronic commerce, this let this party (2013) in the study of regional level of e-commerce development measure put forward the measurement system, to measure the area of electronic commerce application degree. Zhang (2007), Fan (2008), Mou(2006), have put forward the positive role of e-commerce on international trade, believe that e-commerce has changed the mode of trade in international trade, operation mode and operation mechanism, has a positive impact on foreign trade companies and production enterprises, increase the international trade management main body, changed its form. At the same time, it also pointed out the impact and challenge on the legal and technical level in the face of these great changes.

\section{Questionnaire and Data Processing}

Questionnaire Designing. According to the purpose of this research, the research designed the "ethnic minority regions in our country electronic commerce application status survey questionnaire focus on China's foreign trade enterprise application of e-commerce in foreign trade activities and through the situation and the problems of e-commerce to expand exports. Questionnaire content mainly involves two aspects trading process and legal norms, which is divided into four parts: the basic situation of enterprise information, general choice, for enterprises of different types of special problem and other problems.

The theoretical basis of the questionnaire design and related experience in the ministry of commerce and other departments on the implementation of e-commerce retail outlet Suggestions about policy support national regions "(2013) have important embodiment, the advice for customs declaration, inspection, tax, pay and credit system are put forward to support policy.

Data source and processing. In this questionnaire, there were 1,500 questionnaires and 1,327 questionnaires, including 1214 valid questionnaires. Considering the number of According to the analysis of the needs of different regions of E-commerce application in national regions, therefore, eliminate no name and is not sure of the region information case, finally determine the actual analysis of 868 questionnaires used. The recycling questionnaire statistics: from the point of view of enterprise scale 21, 125 large enterprises, oversize enterprise 369 medium-sized enterprises, small enterprises, other 26, small and medium-sized enterprise accounting for 80 of the total.

\section{Data Validity Test.}

Data reliability test. In this paper, the reliability analysis method of questionnaire survey was studied in detail. This article by SPSS software Alpha reliability coefficient method is adopted to improve the reliability test, reliability coefficient should be between $0-1$, the questionnaire survey data Cranach Alpha $=0.951$, up to the effective standard, good reliability, show that the internal consistency of the questionnaire.

Data validity test. Validity reflects the degree of authenticity of the concept to be measured. It includes the contentvalidity and the constructvalidity. In this paper, the effective sample data to the Kaiser-Meyee-Olkin (KMO) sample measure and Bartlett (Bartlett) sphericity test, the data: Bartlett the observed value of spherical test statistics for 25461. 112. The corresponding probability $P$ value is close to 0 , while the $\mathrm{KMO}$ value is 0.931 , indicating that the validity of the questionnaire is acceptable.

\section{Evaluation Index Correction and Application}

Revision of Evaluation Indicators. In the KMO value and Bartlett spherical test of the sample, the closer the KMO value is to 1 , the more relevant the correlation degree between variables is, the more 
suitable for factor analysis. At the same time, the null hypothesis of the sphericity test is independent and cannot extract the common factor if accepted. According to the validity of the test the data can be handled, the survey data of KMO value is close to 1 and examine the $\mathrm{P}$ value is 0 , spherical reject null hypothesis, suitable for factor analysis shows that the questionnaire data.

For maximum variance factor loading matrix orthogonal rotation after get of the rotating factor loading matrix, can reflect the public factor and the relationship between the variables, and according to the factor loading quantity of extraction factors are named, it is concluded that the index of 8 class in table 3 (common factor). Using the regression method to obtain single factor Fi $(I=1,2 \ldots,(8)$ score function by SPSS software for factor score matrix), and the proportion of each factor accounted for the total variance of variance as weights to get the comprehensive factor score formula:

Table 1 Total variance decomposition

\begin{tabular}{|c|c|c|c|c|c|c|}
\hline \multirow{2}{*}{ Factor } & \multicolumn{3}{|c|}{ Initial characteristic root } & \multicolumn{3}{c|}{ After orthogonal rotation } \\
\cline { 2 - 7 } & Eigenvalue & $\begin{array}{c}\text { Variance } \\
\text { Contribution }\end{array}$ & $\begin{array}{c}\text { Cumulative } \\
\text { Contribution }\end{array}$ & Eigenvalue & $\begin{array}{c}\text { Variance } \\
\text { Contribution }\end{array}$ & $\begin{array}{c}\text { Cumulative } \\
\text { Contribution }\end{array}$ \\
\hline 1 & 14.66 & 34.695 & 33.654 & 7.754 & 17.559 & 17.554 \\
\hline 2 & 5.452 & 11.547 & 45.654 & 4.987 & 11.364 & 28.896 \\
\hline 3 & 3.044 & 6.547 & 52.147 & 4.651 & 10.541 & 39.157 \\
\hline 4 & 2.867 & 6.321 & 58.341 & 4.452 & 10.129 & 49.365 \\
\hline 5 & 1.574 & 3.672 & 63.184 & 3.3547 & 7.624 & 57.158 \\
\hline 6 & 1.351 & 3.147 & 65.778 & 2.354 & 5.129 & 62.325 \\
\hline 7 & 1.154 & 2.654 & 67.549 & 1.987 & 4.3698 & 66.428 \\
\hline 8 & 1.055 & 2.141 & 70.1587 & 1.478 & 3.487 & 70.354 \\
\hline
\end{tabular}

$\mathrm{F}$ total $=\left(0.17557 \mathrm{~F}_{1}+0.11240 \mathrm{~F}_{2}+0.10570 \mathrm{~F}_{3}+0.10132 \mathrm{~F}_{4}+0.7700 \mathrm{~F}_{5}+0.5118 \mathrm{~F}_{6}+0.04375 \mathrm{~F}_{7}\right.$ $\left.+0.03400 \mathrm{~F}_{8}\right) / 0.70092$

Corresponding to each factor is a reflection of the original variables can be found that the combination of the original variable does not change substantially questionnaire design when the initial classification of evaluation indexes, based on the combination of experience and mathematical method, named after the new system of secondary indicators, resulting in ethnic minority regions development level evaluation index system of constructing e-commerce.

Index System Analysis. The evaluation index system of e-business development in China's ethnic regions is divided into two levels, including eight level indexes, including 15 secondary indexes. Index system of correction in the process of the classification of secondary index did not change, but the original index of different factors influencing the degree of separation, reflects the factors impact on the level of e-commerce in national regions and the importance.

Thus summed up five e-commerce in ethnic regions has important influence on indicators: e-commerce law factor, the electronic payment tools and the $1 / \mathrm{c}$ factor, international market environment factor, electronic customs clearance factor and e-commerce logistics factors. Did not influence factors in the evaluation index of the preliminary design of the importance of sorting or comparison, and specific weight value in the modification of the survey data to improve the deficiency, the influencing factors of weight is determined by the variance contribution ratio of the common factor, its importance in the factor weight in table 3.

The above analysis shows that in this paper, the investigation questionnaire of variables in the design of the secondary classification is reasonable, some level of classification can be refinement, and ranking should be based on the impact of important. The results of the survey results do not change the overall structure of the evaluation system, but make it more perfect.

According to the weight and ranking of common factors, it can be seen that the advantages and disadvantages of e-commerce legal environment play a crucial role in the development of e-commerce in ethnic regions. The vigorous development of electronic commerce in creating wealth, opening up new markets at the same time, also caused a significant impact to the current legal system, legal system put forward the severe challenge to the original, exposed many gaps and shortcomings in the current laws and regulations. About the legal issues of e-commerce in national regions has caused extensive concern 
of the international community, and has carried on the certain research and discussion, proposed corresponding policies and regulations can be used as a reference for relevant legislation in China. But by the particularity of economic environment in each country, our country electronic commerce in ethnic regions of the research on the laws, regulations and policies and implementation steps still need to intensify, as soon as possible to complete the establishment and perfection of legal system, to safeguard national regions in the development process of e-commerce is not constrained by legal issues.

Ethnic minority regions in China is the establishment of e-commerce pilot that e-commerce has gradually in ethnic regions, and China Free Trade Area is also proposed to speed up cultivating e-commerce service function in national regions; In the rapid development of e-commerce in minority regions, many experts and scholars have pointed out that policies, customs clearance and logistics are the bottlenecks of developing e-commerce in ethnic regions. Through the index system of correction process can be found that the weight of the indicators is indeed reflects the importance of restricting the development of, but the index system also shows that the influence of the international market environment also should cause our attention.

Application Analysis. The evaluation index system and comprehensive scoring formula from the previous study can examine the application level and main problems of e-business in different regions of China. According to the data from questionnaire according to the regional division, questionnaire data involved a total of 27 provinces and cities, but because of some provinces and cities the number of samples within 10, will not be able to represent the region's comprehensive level of e-commerce development in national regions, so only nine to sample size is more than 10 provinces and cities for ranking. In table 4, F1 F8 represents the score of eight first-level indexes in the evaluation index system, and the comprehensive development level score of $\mathrm{F}$ is the ranking of comprehensive scores. A negative score indicates that the area is below average.

Around the Table 2 provinces and cities in the comprehensive ranking and the actual level of qualitative analysis of e-commerce development in national regions is a whole is relatively consistent, illustrate the questionnaire in the process of the construction of the evaluation index system to comprehensively considering all factors affecting e-commerce in national regions, and the questionnaire survey data of high reliability, the evaluation system of the fixed play a positive role. According to constructed the evaluation index system, and the application of the data from questionnaire analysis, can be more scientific and visually analyzed at present, China's overall and ethnic minority regions around the development situation and the existing problems of electronic commerce.

Table 2 comprehensive scores and rankings of e-business in regional ethnic regions.

\begin{tabular}{|c|c|c|c|c|c|c|c|c|c|}
\hline Regions & $\mathrm{F} 1$ & $\mathrm{~F} 2$ & $\mathrm{~F} 3$ & $\mathrm{~F} 4$ & $\mathrm{~F} 5$ & $\mathrm{~F} 6$ & $\mathrm{~F} 7$ & $\mathrm{~F} 8$ & $\mathrm{~F}$ total \\
\hline Gansu & 0.057 & 0.214 & 0.258 & -0.145 & -0.114 & 0.098 & 0.014 & -0.324 & 0.052 \\
\hline Xinjiang & 0.001 & 0.145 & -0.258 & 0.146 & 0.368 & -0.217 & 0.154 & 0.214 & 0.046 \\
\hline Qinhai & 0.269 & -0.354 & -0.269 & 0.128 & 0.364 & 0.128 & 0.247 & 0.214 & 0.047 \\
\hline Shanxi & 0.214 & -0.354 & 0.325 & 0.851 & -0.247 & 0.965 & -0.244 & 0.2542 & 0.049 \\
\hline Guizhou & -0.57 & 0.544 & -0.36 & -0.84 & -0.98 & 0.14 & 0.245 & -0.354 & -0.145 \\
\hline Ningxia & 0.364 & 0.258 & 0.417 & 0.254 & -0.654 & 0.258 & 0.164 & 0.574 & -0.058 \\
\hline $\begin{array}{c}\text { Inner } \\
\text { Mongolia }\end{array}$ & -0.324 & -0.354 & 0.125 & 0.341 & 0.145 & -0.321 & 0.254 & 0.115 & -0.068 \\
\hline
\end{tabular}

\section{Conclusions and Suggestions}

As an important branch of e-commerce, e-commerce in ethnic regions is an important means for Chinese enterprises to carry out international trade and has become an important breakthrough point in the development of e-commerce in China. By constructing the evaluation index system of e-business application in China's national regions, this paper clarifies the key indicators that should be paid attention to in the development of e-commerce in China's ethnic regions. In view of the above analysis, this paper argues that, to improve our country enterprise electronic commerce application ability in national regions is a long-term and arduous task, in order to improve the level of development in the first place to 
the influential factors of the development and influence degree has a full understanding of this work is through the establishment of evaluation index system of electronic commerce development in national regions. According to this article conclusion, the support of national policies and relevant laws and regulations in which play a crucial role, around the level of development for regional natural factors, laws, regulations and policies related to environmental factors such as cause bigger differences, countries should pay more attention to e-commerce development in national regions are relatively backward regions, perfect the policy of form a complete set of rules and regulations; To relatively weak link, attach importance to the research in the process of logistics and customs clearance is more adapt to the development of new ideas, new ways of exploring more advantage, solve the bottleneck problems in electronic commerce development in national regions, comprehensively promote the foreign trade enterprise electronic commerce application level in national regions, to promote China's foreign trade import and export business faster progress through network channels.

\section{Acknowledgements}

This work was supported by the Modernization and Social Harmonious Development in Ethnic Regions: Research and Innovation Team of Northwest Minzu University (Grant No: 31920180101) and by the Key Laboratory of E-commerce of Ethnic information in Gansu Provincial (Grant No:MDS2017001) and Comprehensive experimental teaching center in Economics (Grant No. 2016XJSYJXSF2X-01-10019109).

\section{References}

[1] Chen Weiwei, The empirical analysis of the construction of the infrastructure construction of university informatization, Journal of Shanghai University of Science and Technology, 2013.

[2] Fan Jiangbo, the influence of e-commerce on international trade and the countermeasures of China. Time Trade, 5 (2008)149-153.

[3] Li Dingzhen, empirical research on the growth evaluation of listed retail enterprises in China, based on factor analysis, the 11th issue of Finance and Trade Economics, 2007.

[4] $\mathrm{Ma} \mathrm{Li}$, Analysis of GDP forecast and policy recommendations in Shaanxi province, Journal of Economic Research, 4 (2012)60-71.

[5]Mou Xiaogang, the application and problems of e-commerce in international trade, science and technology plaza, 2006.

[6]Ren Zhengfang, research and demonstration of the measurement method of regional e-commerce development, Journal of Lanzhou Education College, 3 (2008) 200-211.

[7]Wang Chenghui, the diagnostic index system and its application of China's insurance competitiveness, Nankai Economic Research, 3 (2017) 20-27.

[8] Zhu Qirong, evaluation index construction and empirical research on the growth quality of China's foreign trade, the 12th issue of finance and trade economics, 2012. 